Int. J. Electrochem. Sci., 13 (2018) 3997 - 4025

\title{
The inhibition Activity of 1,10 - bis(2-formylphenyl)-1,4,7,10- tetraoxadecane (Ald ) and its Schiff base (L) on the Corrosion of Carbon Steel in HCl: Experimental and Theoretical Studies
}

\author{
Lamia Boucherit $^{1, *}$, Tahar Douadi ${ }^{1}$, Nadjib Chafai $^{1}$, Mousa Al-Noaimi $^{2}$, Salah Chafaa ${ }^{1}$ \\ ${ }^{1}$ Laboratoire d'électrochimie des matériaux moléculaires et complexes (LEMMC), Département de \\ Génie des Procèdes, Faculté de Technologie, Université Ferhat ABBAS de Sétif-1, 19000 Sétif, \\ Algeria \\ ${ }^{2}$ Department of Chemistry, Hashemite University, P.O. Box 150459, Zarqa 13115, Jordan \\ *E-mail: boucheritlm49@gmail.com
}

doi: $10.20964 / 2018.04 .59$

Received: 31 December 2017 / Accepted: 7 February 2018 / Published: 6 March 2018

The inhibitor effect of aldehyde and their Schiff base ligand on the corrosion of XC48 carbon steel in $1 \mathrm{M} \mathrm{HCl}$ solution was investigated using weight loss measurements and electrochemical Methods. These compounds are an efficient corrosion inhibitors and their inhibition efficiency are increased with increasing inhibitor concentration. The Adsorption of these compounds on carbon steel surface obeys Langmuir's isotherm. The surfaces of carbon steel after exposing to test solutions were examined by atomic force microscopy. The quantum chemical parameters were calculated using the density functional method. The interaction between the Fe(100) surface and the inhibitors were performed by molecular dynamics simulations.

Keywords: Schiff base, DFT, MDS, AFM, Corrosion inhibition.

\section{$\underline{\text { FULL TEXT }}$}

(C) 2018 The Authors. Published by ESG (www.electrochemsci.org). This article is an open access article distributed under the terms and conditions of the Creative Commons Attribution license (http://creativecommons.org/licenses/by/4.0/). 